\title{
LAS DOS VÍRGENES BRASILEÑAS: \\ lo local y lo global en el culto mariano*
}

\author{
Rita Laura Segato \\ (Tania Mara Campos de Almeida y Mónica Pechincha) \\ DEPARTAMENTO DE ANTROPOlOGía-UniversidAd dE BRASILIA \\ rsegato@terra.com.br
}

\begin{abstract}
Resumen
- STE ARTÍCULO EXAMINA LAS DIFERENCIAS ENTRE LA VIRGEN DE LA DEVOCIÓN POPULAR [ brasileña, representada en este análisis por una aparición que ha venido ocurriendo desde 1987 en el interior del estado de Minas Gerais y la Virgen utilizada por los miembros del Movimiento Católico Carismático para señalizar su pertenencia a la Iglesia, la imagen de Nuestra Señora de la Paz, aparición de Medjugorje. A pesar de ser ambas católicas, una es un símbolo pleno y representativo de la tradición local como alteridad histórica propia del catolicismo popular brasileño; en cuanto la otra, se comporta como icono o emblema para demarcar la identidad política de los católicos en su confrontación del avance evangélico.
\end{abstract}

\begin{abstract}
T HIS ARTICLE EXAMINES THE DIFFERENCES BETWEEN THE VIRGIN OF POPULAR BRAZILIAN devotion represented in this analysis by an apparition that has been occurring since 1987 in the interior of the state of Minas Gerais, and the Virgin used by the members of the Charismatic Catholic Movement to signal their membership in the church -the image of Our Lady of Peace, apparition of Medjugorje-. Despite the fact that both are Catholics, one is a full symbol, polysemically representative of the local tradition as historic alterity of popular Brazilian Catholicism, while the other behaves as an icon or emblem to demarcate the "political identity" of Catholics in its confrontation with the evangelical advance.
\end{abstract}

Revista Colombiana de Antropología

Volumen 37, enero-diciembre 200I, pp. 90-III 


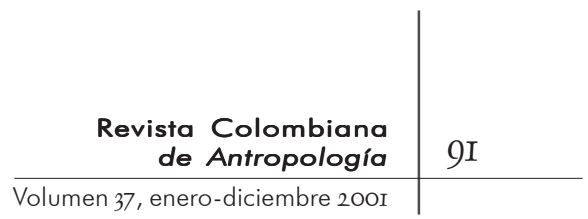

Un N RECURSO HABITUAL EN LOS ANÁLISIS DEL MOVIMIENTO DE LA RENOvación Católica Carismática (RCC) ha sido utilizar como término de comparación el pentecostalismo evangélico, como lo hicieron para el Brasil Pierre Sanchis (1994), Ari Oro (1996) y Maria das Dores Campos Machado (I996), entre otros. Éste último constituye, sin lugar a dudas, la contraparte esclarecedora que, por semejanza y contraste, permite percibir con más claridad el resurgimiento del carisma en el catolicismo. Sin embargo, en este ensayo la comparación se orienta en

*Este texto fue preparado con la colaboración de dos estudiantes de doctorado en el programa de posgrado en antropología de la Universidad de Brasilia, Tania Mara Campos de Almeida y Mónica Pechincha.

Agradecemos a Juliana Pechincha, joven mística católica, hermana de una de las colaboradoras en este ensayo. otra dirección y el análisis se centra en el contraste entre las dos vírgenes brasileñas, la María de la devoción popular y la de los carismáticos.

Para eso me apoyaré en documentos y folletos sobre la Renovación Carismática (CNBB, I994; Lubel, s./f.; Servos da Rainha, I994) y en la manifestación mariana descrita y analizada por Tania Mara de Almeida en su tesis La gestación de un mito: la aparición de la Virgen María en Piedade dos Gerais (I994). La articulación entre los dos mundos se desarrollará a partir de la orientación de Juliana Pechincha, quien frecuenta ambos ambientes y defensora convicta de la unidad del catolicismo por medio de la variedad de sus prácticas y comunidades. Esta joven, actualmente de veintidós años, guardó ayuno durante cerca de dieciocho meses, durante los cuales visitó varios santuarios y solo durmió por periodos breves, en el piso de mosaico de las iglesias del Distrito Federal. Por solicitud de su hermana, regularmente se hizo exámenes de sangre y, a pesar de haberse alimentado durante esos meses esporádicamente con trocitos de pan y agua, su condición de salud no se alteró.

\section{LA VIRGEN DE LOS CARISMÁTICOS Y LA VIRGEN DE PIEDADE}

AS GENERALIDADES SOBRE EL ORIGEN Y LA DIFUSIÓN DEL MOVIMIENTO de la Renovación Católica Carismática (RCC) son de conocimiento público. Surgió en Estados Unidos de Norteamérica en los años 1970, para expandirse inmediatamente por el mundo 


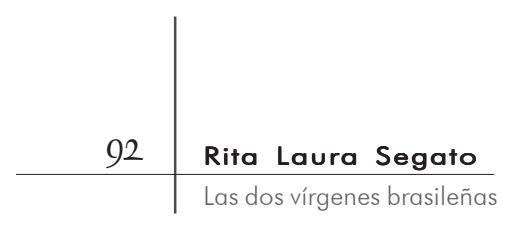

entero con apoyo de la jerarquía católica, aun cuando mantiene algunos conflictos de orden litúrgico con el Vaticano. Estos conflictos son de una magnitud incomparablemente menor que los de orden teológico, característicos de la tensión entre la Teología de la Liberación y el Vaticano. En Brasil, la Virgen a la cual rinden culto los participantes del movimiento es Nuestra Señora de la Paz, que apareció por primera vez en Medjugorje, antigua Yugoslavia en I98I, dando diariamente mensajes desde 1984. El Vaticano no se ha pronunciado todavía sobre esta manifestación mariana, pero ella cuenta con el apoyo del clero brasileño, sin encontrar obstáculos para su difusión en el país.

La manifestación de Piedade dos Gerais, cuyo evento llegué a presenciar, ocurrió por primera vez en I987 pero alcanzó su estructura definitiva y actual en I988. Ésta tiene lugar en una pequeña hacienda en los alrededores del pueblo de Piedade, distrito de aproximadamente tres mil habitantes, a 70 kilómetros por camino de tierra de Belo Horizonte, capital del estado de Minas Gerais. Por las características del camino esa localidad puede considerarse aislada.

La pequeña hacienda es de propiedad de don Antonio, padre de tres de los cinco videntes iniciales, diácono de la parroquia de Piedade y, en los años I980, asiduo participante de la comunidad de base organizada en la localidad por una monja misionera. Tanto el párroco franciscano, como la religiosa responsable de la comunidad eclesial de base (CEB), dieron la espalda al fenómeno inmediatamente.

Inicialmente, tres niñas -dos hermanas y una prima-, la mayor, Marilda, de diez años en aquella época, volvieron un día de sus juegos en la campiña de la hacienda diciendo haber visto a una señora. En poco tiempo, los videntes serían cinco: tres niñas y dos niños -cuatro hermanos y una prima-, quienes pasan a encontrar a la Señora diariamente. En las manifestaciones filmadas entre 1987 y I988 los niños leen a la vez un mensaje escrito por la señora con una varita en el cielo. Recitan esta lectura moviendo los labios de forma simultánea. A partir de mayo de I988, la niña mayor, Marilda, dice leer los labios de la Virgen cuando enuncia el mensaje dos veces por día, de mañana y de tarde, con la regularidad de un reloj. El efecto es el de una virgen que habla por medio de la niña, por su boca. Por tanto, la peculiaridad de esta manifestación mariana brasileña es que, en su aspecto aparente, la niña se presenta a su audiencia poseída por la Virgen, manteniendo, en este sentido, una relación evidente con el ambiente 


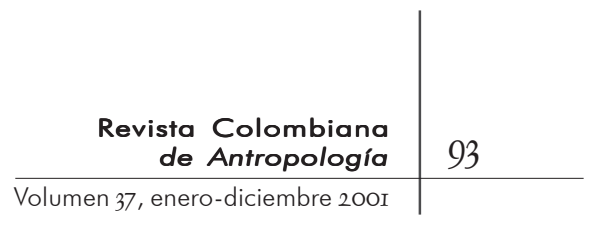

fuertemente espiritista del Brasil. Sus mensajes, de tantos años, pueden agruparse en tres periodos:

I. Periodo de directivas para la organización de la comunidad devocional, durante el cual la Virgen forma su familia. En esta época los mensajes son íntimos, para el grupo local, y orientan a los devotos para residir en una habitación colectiva, separados por sexo, abierta a los extraños que quieran sumarse pero cerrada al clero y a los comerciantes y hacendados locales: quedan excluidas la riqueza y la jerarquía.

2. La Virgen autoriza la construcción de casas separadas en lo que fueron terrenos de la pequeña hacienda de don Antonio, pero con la condición de que permanezcan abiertas y disponibles para quien necesite ocuparlas. Los mensajes continúan centrados en la vida cotidiana de la comunidad que reside en el local.

3. El mensaje se abre al mundo, incluyendo ahora a los que detentan el poder local, y cobra un carácter más genérico.

Sin embargo, durante estos periodos la Virgen no modifica el espíritu fundamental de su mensaje, que colectiviza la propiedad, prohibe el trabajo productivo, abre la pequeña hacienda a todos los peregrinos que quieran albergarse en ella, especialmente a las prostitutas, niños de la calle y mujeres solteras embarazadas. El dueño, don Antonio, obedece todas estas orientaciones y su hacienda se transforma en un pequeño poblado de una calle con dos hileras de casas, con puertas sin cerraduras, abiertas a los peregrinos, y una cocina comunitaria. Convergen allí y se asientan miembros de todos los estratos sociales y regiones del país, como una familia de joyeros y otra de banqueros, artistas, obreros, niños abandonados, prostitutas, campesinos pobres y empleados públicos.

La Virgen tampoco deja, en momento alguno, de intercalar, en sus poéticos mensajes, recados particulares y muy personales para el grupo íntimo de los residentes en la pequeña villa: no hurgarse la nariz o sacarse los piojos durante su presencia, además de felicitaciones de aniversario y recomendaciones de higiene, como por ejemplo instrucciones para barrer mejor el patio o no dejar el plato mal lavado, etcétera. En los mensajes, lo 
cotidiano, lo doméstico y lo profano se confunden y entrelazan con lo sagrado, lo trascendental y lo sobrenatural.

\section{VÍNCULO Y DIFERENCIA ENTRE LAS DOS VÍRGENES}

OS NEXOS Y PARENTESCOS ENTRE PRÁCTICAS Y DEVOCIONES QUE, EN su origen, estructura e inspiración no guardarían, en principio, L una relación estrecha, se generan por la participación de devotos fieles como Juliana. Fenómenos que pertenecen, en efecto, a órdenes distantes, inconmensurables de la experiencia, a pesar de formar parte del mundo católico, como el caso de las dos vírgenes brasileñas, sin querer con esto realizar un ejercicio que enfatiza la oposición entre una Virgen popular y una de la elite como en el análisis que hace Terry Rey para el culto mariano en Haití (véase Rey, 1999).

Preguntamos a Juliana -cuya inmersión en la tradición católica es profunda, tanto por su trayectoria personal cuanto por el catolicismo militante de su familia- cuál es la diferencia entre la manifestación mariana de Piedade y la devoción de los carismáticos a la Virgen. Y ella nos da de inmediato las dos respuestas que permanecerán en múltiples desdoblamientos: la primera, innegociable por decreto, afirma tratarse de la misma y única Virgen, pues no existe más que una. Esta respuesta permanece como enunciado formal de la unidad de la Iglesia católica y de la indivisibilidad de lo que de sagrado representa. Por debajo de este enunciado formal la segunda respuesta surge, fecunda en matices, enigmática. Juliana dice:

La Virgen de Piedade está en el tiempo; la de los carismáticos no está en el tiempo. Al solicitarle una exégesis nativa de la noción de tiempo que utiliza, explica:

"La Virgen de Piedade dos Gerais saca a las personas del tiempo común, de nuestro tiempo. Las ubica en un tiempo en el que nada más se necesita. La de los carismáticos existe aquí, ahora, las personas necesitan ser reconfortadas, necesitan de música, gestos, apoyo, consuelo, bienes materiales".

Así, la Virgen de Piedade ya está en el tiempo de la salvación, en un tiempo posapocalíptico, en que las cosas terrenas, materiales, no tienen valor, en el cual ya no es necesario el consuelo. 


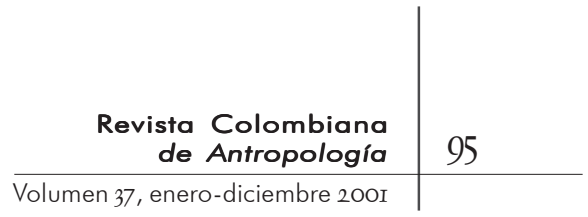

La reina de la Paz, Nuestra Señora de los carismáticos, existe en este tiempo. Sus mensajes son para nuestro propio tiempo. Los devotos todavía buscan reconfortarse, consolarse, con música, danzas, gestos.

Sobre el significado de el tiempo, Juliana dice: "Nuestra señora pidió expresamente para que nosotros, que estamos en el mundo, no intentemos imaginar el tiempo. Ella nos pide que vivamos la vida de Dios ahora, en las peores circunstancias. Nuestra obligación es hacer el cielo ahora, en el mundo”.

Entre tanto, Piedade dos Gerais ya se encuentra in illo tempore, en aquel tiempo, que ella define como "un tiempo sin tiempo, el tiempo del Evangelio, tiempo de Jesús en el mundo". E ilustra la idea de 'tiempo' con la siguiente cita de los Evangelios: "Habrá un tiempo en que el Reino de Dios será restituido. El tiempo es éste”. Ese es, según Juliana, el tiempo de la comunidad de Piedade, "principio y final de historia”. En suma, la noción de tiempo se refiere a la salida del tiempo histórico y a la entrada en uno utópico en el que el principio y el fin son uno solo, cuando la historia sagrada, el kerigma, se presenta y produce el efecto de que el presente se coloca en coincidencia y contigüidad con la misma, lo que siempre es consecuencia de una recontextualización espacial de eventos bíblicos.

A partir de la oposición establecida por Juliana dentro de un horizonte de unidad fundadora fui hilando, articulando, una serie de equivalencias. Aplico, como es idiosincrático del método antropológico, el principio hermenéutico de caridad a la proposición nativa en el sentido estrictamente filosófico de acreditarle sentido, aun cuando, inicialmente, no vislumbremos el ámbito a que ese sentido nos reporta. El principio de caridad reza que toda proposición nativa tiene sentido y validez, y el trabajo del hermeneuta es encontrarlo, rastrear las pistas textuales para hacer un mapa del territorio que diseñan. Para eso, uso la contraposición formulada por Juliana entre estar en el tiempo y no estar en el tiempo, como llave hermenéutica capaz de abrir la caja hermética de los sentidos implicados en el pensamiento de la informante.

Sin duda, el discurso de Juliana es un discurso de naturaleza oracular, sintética, compacta, que necesita ser desplegado e interpretado. 
L DISCURSO DE JULIANA SUGIERE NUMEROSOS DESDOBLAMIENTOS DE - la noción de tiempo, y la intertextualidad de sus enunciados L con los de otros devotos de ambas vírgenes revela sus múltiples significados: tiempo parece hablar de espacio geográfico, de comunidad, de vida económica, de cultura, de relaciones de género y edad, de estilos de sociabilidad. Tiempo, en esta forma de hablar, se entreteje también con el discurso teórico sobre historia bíblica y experiencia cristiana. De hecho, como nativa, Juliana hace uso de un concepto recurrente en la propia teología cristiana, en la teoría de la religión en general y en los análisis antropológicos del catolicismo popular.

Sólo para citar algunos de los momentos en que el tema del tiempo sagrado en el mundo cristiano aparece tratado, recordamos que en el ensayo sobre el mal entre los campesinos brasileños, Otávio Velho afirma que el discurso bíblico es presentificado constantemente como texto de una experiencia universal, su pre-texto (Velho, 1995). Por mi parte, al intentar entender la conversión al protestantismo en comunidades de la Argentina caracterizadas por la fuerte presencia del catolicismo andino tradicional, observé que los fieles situaban el tiempo bíblico, las buenas nuevas, en el paisaje local contemporáneo, o sea, se producía una contienda palpable entre eventos presentes y eventos bíblicos (Segado, I99I). Más recientemente, el inspirado análisis de Carlos Steil afirma que en los sitios de peregrinación el espacio presentifica el tiempo: en las romerías, la entrada en el tiempo bíblico, de salvación, se realiza por medio de la entrada en el espacio sagrado del santuario (Steil, 1996).

En el campo de la filosofía, Henrique de Lima Vaz sistematiza el conjunto de ideas que se encuentran por detrás de esta experiencia tan particular del tiempo:

el cristianismo operó una revolución profunda en la representación del tiempo [ ... ] el tiempo cristiano sólo conoce un 'moderno' que no pasa: el hecho de Cristo. Así, pues, podemos decir que las civilizaciones no-filosóficas son anacrónicas pues se remontan permanentemente a la identidad de un tiempo originario. La civilización filosófica -la nuestra- es diacrónica pues hace constantemente del modo temporal, del ahora, el mirador histórico privilegiado para medir y juzgar el tiempo. El cristianismo es 


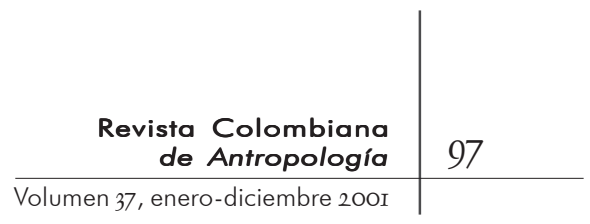

catacrónico, pues recupera y salva el tiempo que fluye refiriéndolo a la singularidad irrepetible y única -al ahora permanente- del evento del Cristo como evento salvador (Vaz, I992: 86).

A partir de esta primera discusión de la categoría tiempo podemos volver a examinar algunas categorías sociológicas que nos sirven para pensar el abismo existente entre las dos vírgenes. La oposición historia/tiempo puede, entonces, ser transpuesta en una serie de otras oposiciones analógicas, que pasan a desarrollar el sentido de la propuesta de Piedade en oposición a la propuesta carismática.

El MUNDO COMO Él ES EN LA RCC

Y EL MUNDO TRANSFORMADO DE PIEDADE

E:

L MUNDO COMO ÉL ES, EN EL CUAL LA RCC PARTICIPA, ES EL DE LA sociedad moderna, mediática, consumista y capitalista, caracterizada por ocultar obsesivamente la muerte. Esta obsesión, funcional en el capitalismo en el que la muerte introduce el detenimiento del proceso de producción y consumo, se vuelve evidente en el mayor conflicto que los carismáticos mantienen con la jerarquía católica: el conflicto con respecto a la liturgia. El ritual carismático introduce cantos y gestos festivos en la propia hora de la eucaristía, eludiendo el reconocimiento de la muerte real que allí ocurre, lo que les ha valido repetidas amonestaciones y llamados de atención (CNBB, I994: 22).

En Piedade, por su parte, no hay ocultación de la muerte, sino su trascendencia. Desde su formación, la pequeña villa vive fuera de las leyes de la producción y el consumo, en un tiempo postulado como eterno.

\section{LA CONDICIÓN SUBALTERNA Y LOS REQUISITOS PARA LA GLOBALIZACIÓN DE LO SAGRADO}

S PRECISO DECIR QUE EL LUGAR DE PIEDADE Y EL DE MEDJUGORJE NO
son conmensurables, permutables social, económica o geo-
políticamente. En su calidad de santuario, Piedade delimita un
espacio radicalmente local, sin equivalencias. Una característica 


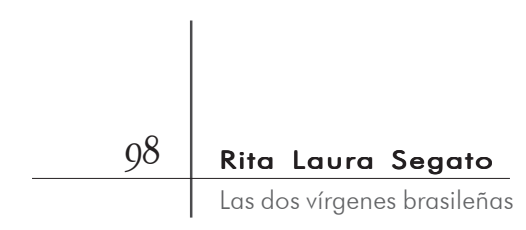

importante de los espacios sagrados es que pertenecen al régimen de las oiconomias, o sistemas donde los flujos y las transacciones permanecen vinculados a su hábitat, a su paisaje, en un tipo de contacto irreductible en términos de equivalencias temporales, económicas. En otras palabras, son remisos a cualquier cálculo que implique la intervención de lo que Baudrillard llama "equivalente universal”, o sea, un mediador universal de equivalencias, una caución fija cuya referencia permita su permuta por otro espacio equivalente. Las leyes del espacio sagrado no son plenamente económicas, en el sentido de la producción y el comercio moderno; solamente tienen valor de uso pero no valor de cambio. Por eso fuerzan a la peregrinación, necesariamente, como salida sine qua non, del tiempo productivo y económico. La Virgen de Piedade no se aparta de este espacio y sus inmediaciones. Sus videntes viajan y han visitado, ya, algunas ciudades brasileñas, pero el arraigo del fenómeno, con todos sus atributos, se mantiene irreductiblemente localizado.

Por su parte, Nuestra Señora de la Paz de Medjugorje, incluso antes de su legitimación por parte del Vaticano, hace parte de la pequeña galería de las apariciones globales reconocidas por la Iglesia, todas europeas, siete en total, que vinieron en el curso de aproximadamente un siglo a desviar la devoción de los santos por el culto mariano a través de fronteras regionales y naciona${ }^{l e s}{ }^{I}$. Si tienen santuario, si suscitan peregrinaciones, el proyecto que representan es un proyecto global.

Como decía, la Virgen de Piedade y su comunidad son radicalmente locales, arraigadas, difícilmente globalizables y, como

I. De las siete vírgenes cuya aparición la Iglesia reconoce hasta el momento, cuatro son francesas: la de la Rue du Bac Paris (I830), La Salette (I846), Lourdes (I858) y Pontmain (I870); una portuguesa: Fátima (I9I7); y dos belgas: Beauraing (I932 a I933) y Banneaux (I933). mostraré más adelante, su condición de emergencia en el contexto del clero local es muy distinta de la condición de Nuestra Señora de la Paz. Lo que nos conduce a una reflexión interesante sobre las relaciones entre pueblo, elites y jerarquía clerical en Brasil. Volveré a esto en seguida, pero baste mencionar aquí la frase repetida por el párroco de Piedade dos Gerais: "Nuestra Señora está apareciendo, sí, pero allá lejos”, haciendo alusión a la aparición de Medjugorje, en detrimento de la aparición local. Por otro lado, en el sector militar urbano de Brasilia, capital del país, ya se construyó una iglesia de Nuestra Señora de la Paz. 


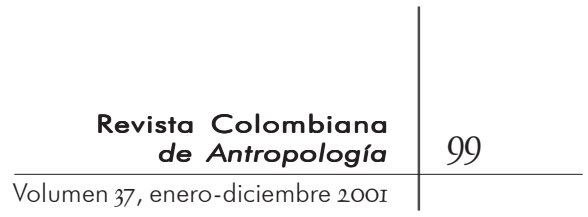

Transformando lo dicho por Juliana, podría concluirse que lo local está en el tiempo, y lo global está fuera del tiempo, pertenece a la banalidad de la historia.

\section{VIDA Y APOCALIPSIS}

[ n cuanto Nuestra Señora de La Paz y otras vírgenes consa- gradas enuncian, junto al mensaje amoroso y de salvación, - uno amenazador y apocalíptico, en Piedade florece una teología singular. Es interesante que en esa pequeña localidad, y al abrigo del ocio productivo, niños y adultos, campesinos y empleados públicos, peregrinos y moradores locales se han puesto a reflexionar, libremente, en la brecha de las instituciones que controlan y disciplinan el pensamiento religioso, buscando y debatiendo nuevas soluciones teológicas, nuevas imágenes, nuevos valores y, sobre todo, una concepción universalizable y accesible de salvación para todos. Un bello episodio de la época de la guerra del Golfo, que me relató la autora de la disertación que uso como referencia (Campos de Almeida: comunicación oral), en este texto ilustra el estilo de esta teología popular. Un grupo de devotos discutía una noche sobre el destino de las almas de tantos muertos iraquíes: icómo podrían todos ellos, infieles, no católicos, ser arrojados repentinamente al infierno por esta guerra, sin una oportunidad para arrepentirse? ¿No habría posibilidad de salvación para ellos? Las opiniones se dividían hasta que se constituyó un consenso en torno de una idea lanzada por el señor Antonio, dueño de la pequeña hacienda y padre de los niños videntes: con seguridad en el momento de la muerte todo corazón alcanza el arrepentimiento; todo ser humano se arrepiente instantes antes de morir.

En Piedade ha surgido lo que me parece una utopía infantil, que desentona completamente con la distopía infantil de Salem, que tan convincentemente narrara Arthur Miller. Por otra parte, desentona también con el énfasis apocalíptico de otras apariciones. Se trata en verdad de una virgen festiva, alegre, ni amedrentadora ni dolorosa. La Virgen de Piedade abandonó muy pronto, después de las primeras apariciones, el énfasis en el fin de los tiempos y estimuló el surgimiento de una teología del perdón generalizado. El mal no está muy presente en los mensajes de 


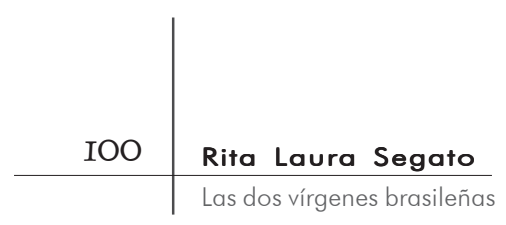

Piedade y tampoco hay curación o cualquier forma de exorcismo, a diferencia de la práctica de la renovación carismática. Ya en el comienzo de las apariciones, Iris, una de las videntes, en ese momento de diez años, anunció que la Virgen venía a dar mensajes y no a curar. Sin embargo, la Virgen ha sido clara en explicar que, siempre, muy cerca de la Virgen y del bien, lo más cerca posible, acecha el maligno.

EL MERCADO Y EL DON

OMO DIJE, ESTAR EN EL TIEMPO, ESTAR EN PiedAde, ES NO PRODUCIR, no trabajar productivamente sino hacer parte de una comunidad atravesada por el flujo del don, donde el mensaje de la Virgen es trocado por el óbolo de los romeros. Limosna y mensaje, entrecruzándose, trazan el circuito de una comunidad de creencia.

Estar fuera del tiempo es estar en el mercado e inscrito en el discurso mediático. La inserción responsiva de los enunciados de la Virgen y sus portavoces en su ambiente contrasta con la reproducción mecánica y la distribución mediatizada de los gestos y las fórmulas discursivas de los carismáticos El mercado no está en el tiempo, el don está en el tiempo.

\section{JERARQUÍA Y SUBVERSIÓN}

DE GÉNERO Y EDAD

A ESCENA FAMILIAR QUE PRECEDIÓ LA APARICIÓN DE LA VIRGEN ERA LA característica y tradicional del patriarcado del interior del es- tado de Minas Gerais: un padre que castiga con vara, un orden doméstico autoritario y jerárquico en lo que respecta a género y edad. En este contexto, María llega para subvertir y reordenar la vida. El padre, señor Antonio, después de un breve periodo de duda y contra la voluntad del propio párroco, de quien era diácono en la iglesia local, pasa a obedecer a los videntes, cuatro niñas y un varón, bajo el liderazgo de Marilda, la mayor, en ese entonces de diez años. En la época en que asistí al fenómeno de la aparición, en abril de 1992, a las tres videntes originales que permanecían se habían sumado dos prostitutas. 


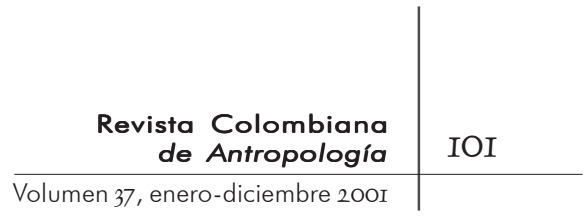

Muy por el contrario, en las comunidades de la renovación carismática, María continúa en el papel convencional de imagen de identificación femenina y de modelo para el comportamiento doméstico y conyugal que le conocemos.

\section{LO MEDIÁTICO Y LO DIALÓGICO}

A EQUIVALENCIA DE RELACIONES ANALÓGICAS SE TRANSPONE AQUÍ A LA oposición entre el patrón gestual de repertorio fijo caracterís- tico de los encuentros de la RCC, y su incorporación de los medios, especialmente de la televisión, con la relación virtual entre seudo-interlocutores que éstos ya introducen. La apariencia de corporalidad nos parece mistificadora, pues se trata de una interlocución no auténtica, en el sentido clásico gadameriano, ya que uno de los interlocutores controla el curso de la comunicación (Gadamer, 1985: 345).

Por ejemplo, en las misas carismáticas del padre Marcelo, un ex profesor de aeróbicos que ha vendido varios millones de discos, en la platea reproduce, imita, como en un gimnasio, los gestos repetitivamente presentados por el pastor frente al altar. Se trata de consignas corporales que marcan la pertenencia a una grey supeditada a la reproducción mecánica de los movimientos de un pastor por definición no dialogante, que propone, como uno de sus emblemas, la imagen siempre presente de Nuestra Señora de la Paz.

Contrasta con esto la presencia inmediata, doméstica, familiar, íntima, de la Virgen de Piedade, cuando aparece diariamente por la mañana y por la tarde: la Virgen de Piedade es sujeto en relación, sujeto de discurso, objeto de cathexis, símbolo encarnado.

En contraposición, la Virgen de los carismáticos entra en el mundo como objeto, referente, signo fijo, emblema, en tanto que símbolo decaído, empobrecido, vaciado de la polisemia característica y vital de los símbolos vivos, densos en sentidos que nunca se agotan. En el culto mediático, el mediador es un comunicador profesional y la eficacia espiritual de su prédica está supeditada a la tecnología de la comunicación (véase Carvalho, I998). 


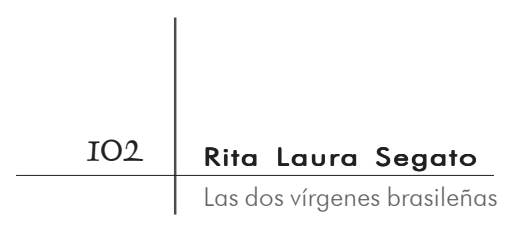

EXCLUSIÓN E INCLUSIÓN:

EMBLEMA CONTRA MENSAJE

$E$ S

EMBLEMA NO ESTÁ EN EL TIEMPO, EL MENSAJE ESTÁ EN EL TIEMPO.

- Si una Virgen es presencia, milagro de la palabra, y la otra es meramente emblema, las consecuencias cobran una magnitud insospechada. Como observa Roland Robertson, en el mundo contemporáneo la religión "se volvió globalmente disponible como fuente de declaraciones de identidad colectiva” (I99I: 289). Me gustaría agregar que esto ocurre no sólo para marcar simbólicamente la unidad de algunas naciones sino también la formación de grupos diferenciados dentro del confinamiento de las fronteras nacionales.

Inspirado en el caso de la India, Ashis Nandy, propone incluso, la distinción entre la dimensión puramente religiosa de la fe como modo de vida, naturalmente pluralista, tolerante y asociada a los pueblos no modernizados, por un lado, y, por el otro, la dimensión ideológica de la religión como "un identificador de poblaciones sub-nacionales, nacionales, trans-nacionales en confrontación con o protegiendo intereses no religiosos, usualmente de carácter político o socioeconómico”, esta última, característica de las poblaciones modernizadas (I990: 70). Nandy enfatiza, con esto, en el carácter reactivo de la religiosidad moderna. Trato este aspecto en mi reflexión reciente sobre opciones religiosas, en la que afirmo que, en algunos sentidos, la afiliación religiosa adquiere una territorialidad semejante a la etnicidad (Segato, 1997).

En su comparación entre católicos carismáticos y pentecostales (1994: 30), Cecilia Maríz y María das Dores Machado documentaron que, para sus informantes carismáticos, la devoción a la Virgen María, junto con la obediencia al Papa, constituyen "la divisoria de aguas, la frontera, y si ésta no es reforzada, no hay por qué permanecer católicos”. Vemos, por tanto, una coincidencia con lo que afirma Pierre Sanchis en su ensayo sobre el desafío pentecostal a la cultura católico-brasileña, en el sentido de que en cuanto el catolicismo tradicional establece una base sincrética para la cultura brasileña, el pentecostalismo introduce una "cierta modernidad" imbuida del principio de unidad, o sea, hace su entrada en el horizonte nacional como identidad marcada por sus purismos (Sanchis, 1994). El catolicismo carismático, al entrar reactivamente en esta escena, dialoga con los 


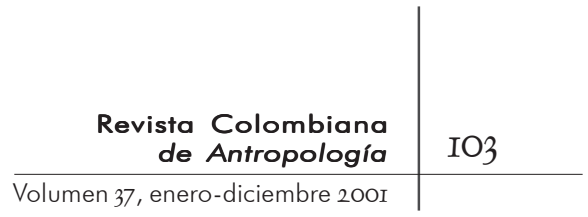

pentecostales, se enfrenta a ellos, aceptando la introducción de un principio de identidad y de unidad, para utilizar los términos de Sanchis.

En el suelo tradicional de Piedade la religión católica obedece a su carácter sincrético constitutivo, y el aspecto reactivo en confrontación con un otro contingente religioso se encuentra ausente. Purismo, identidad y unidad son caracteres modernos, introducidos primero por los pentecostales y luego, a remolque, acatados por los carismáticos como idioma natural de su confrontación.

Piedade presenta una inclusión serena del Otro, podría decirse que una inclusión no traumática. Esto se ve en el hecho de que allí la Virgen habla, literalmente, por la boca de los niños videntes, constituyéndose por tanto en un fenómeno muy próximo a la posesión. Entre los pentecostales el habla del Espíritu Santo en lenguas también se aproxima al suelo espiritista brasileño, pero en lucha con el diablo como enemigo, representado para ellos por los espíritus de macumba. Entra así aquí la identificación negativa, la producción de identidad. Para los carismáticos el habla del Espíritu Santo en lenguas se constituye en la reedición de un catolicismo extático y el drama de la identidad tiene su epicentro en la frontera con los evangélicos, teniendo la Virgen como emblema, y no con las religiones espiritistas brasileñas tradicionales.

En otras palabras, si, por un lado, para los pentecostales el frente principal de oposición son los espiritismos afrobrasileños y sus entidades sobrenaturales tienen un papel emblemático negativo como encarnaciones del diablo; por el otro, el frente principal para los carismáticos son los evangélicos, con la Virgen como icono frente al Jesús de los protestantes. En el suelo tradicional de Piedade no se coloca, como decía Ashis Nandy, el problema de la identidad. Se trata de un suelo sincrético, que engloba al otro, lo incluye incorporándolo sin trauma, presentando un hibridismo sin represión.

Tenemos así constituidos dos tipos de identidad: una que se configura frente a un tercero fijo, convención, referente emblemático para la consolidación de un pueblo -característica ésta de dos identidades globalizadas, o sea de lo que llamo en un artículo reciente de "identidades políticas", en oposición a lo que denomino "alteridades históricas" (Segato, 1999)-. Y la identidad que emerge de una cathexis dentro de un contexto histórico preciso, 


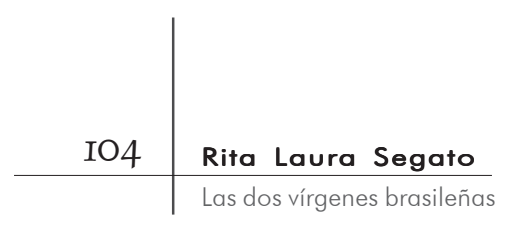

resultante de un juego de inversiones libidinales positivas y negativas, en el sentido de auto-producción en relación a un Otro, a un interlocutor histórico. Me parece, entonces, que ricos y pobres, niños y adultos, mujeres y patriarcas son el contexto habitual y constante de la emergencia de Piedade, mostrando que, en la formación histórica de la diversidad brasileña, éstos son los fraccionamiento estructurantes de la matriz tradicional, premoderna. El emblema fijo, global, de Nuestra Señora de la Paz es una manifestación de la identidad política religiosa de los católicos frente al avance evangélico y, especialmente, pentecostal.

\section{CARISMA GENUINO Y CARISMA RUTINIZADO}

ARA HABLAR DE LAS EXPERIENCIAS DEL ESTAR EN EL TIEMPO Y DEL ESTAR fuera del tiempo de salvación podríamos también invocar las categorías weberianas, y decir que el carisma genuino está en el tiempo y el carisma rutinizado no está en el tiempo. En su discusión de tipos de dominación Max Weber describe el carisma como "la cualidad que pasa por extraordinaria (condicionada mágicamente en su origen [ ... ], de una personalidad, por cuya virtud se la considera en posesión de fuerzas sobrenaturales o sobrehumanas [ ... ]" (I974: I93). En ese contexto, menciona, inclusive, "el carisma de un "poseso". Y se refiere a la dominación carismática pura como aquélla en la que "no hay I: 'sueldo' ni 'prebenda' alguna, sino que los discípulos y secuaces viven -originariamente- con el señor en comunismo de amor o camaradería, con medios procurados por mecenas..."(Ibidem: I95). "[ ... I el profeta genuino, como el caudillo genuino, como todo jefe genuino en general, anuncia, crea, exige nuevos mandamientos, en el sentido originario del carisma: por la fuerza de la revelación, del oráculo, de la inspiración o en méritos de su voluntad concreta..." (Ibidem).

Haciendo eco en la experiencia de Piedade, Weber continúa:

La dominación carismática se opone, igualmente, en cuanto fuera de lo común y extra-cotidiana, tanto a la dominación racional, especialmente la burocrática, como a la tradicional, especialmente, la patriarcal y patrimonial o estamental. Ambas son formas de dominación cotidiana, rutinaria -la carismática (genuina) es específicamente lo contrario-. La dominación burocrática es específicamente racional en el sentido de 


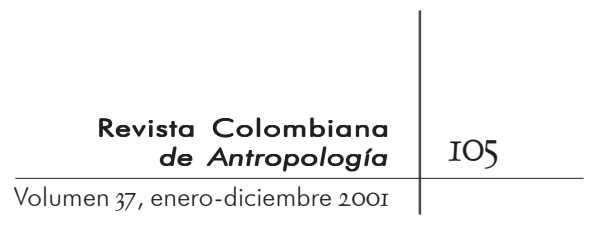

su vinculación a reglas discursivamente analizables; la carismática es específicamente irracional en el sentido de su extrañeza a toda regla. La dominación tradicional está ligada a los precedentes del pasado y en cuanto tal igualmente orientada por normas; la carismática subvierte el pasado (dentro de su esfera) y es en este sentido específicamente revolucionaría (Ibidem).

Por otro lado, la experiencia de la RCC resuena en el texto weberiano sobre "la rutinización del carisma", pues si

en su forma genuina la dominación carismática es de carácter específicamente extraordinario y fuera de lo cotidiano, representando una relación social rigurosamente personal [ ... ]. En el caso de que no sea puramente efímera sino que tome el carácter de una relación duradera, "congregación" de creyentes, comunidad de guerreros o de discípulos, o asociación de partido, o asociación política o hierocrática -la dominación carismática que, por decirlo así, sólo existió en statu nascendi, tiene que variar esencialmente su carácter: se racionaliza (legaliza) o tradicionaliza o ambas cosas en varios aspectos [ ... ] (restableciendo) la existencia familiar... (Ibidem: 197).

Por tanto, al seguir a Weber percibimos que en relación con el carisma no se trata simplemente de oponer vida tradicional a vida moderna, comunidad a urbe o relaciones dialógicas y relaciones mediáticas. El carisma auténtico rompe no sólo con la burocracia moderna sino también con la tradición, con las bases patriarcales de la vida comunitaria, es revolucionario y establece un tiempo de subversión. En este sentido, la experiencia del carisma auténtico se encuentra próxima al estar en el tiempo de Piedade dos Gerais, en oposición a la rutinización de los carismáticos que conviven, aunque en un nicho de acción específico, con las reglas del orden católico institucional y moderno.

\section{Nación, Iglesia y DEVOCióN: \\ LA VIRGEN LOCAL BRASILEÑA \\ Y LA VIRGEN GLOBAL EUROPEA}

N TEXTOS RECIENTES HE PROPUESTO ALGUNAS CATEGORÍAS CON LA IN- tención de precisar las características de los fenómenos de orden local y los fenómenos de orden global en el contexto de la nación. Creo que estas categorías pueden ser aplicadas aquí 


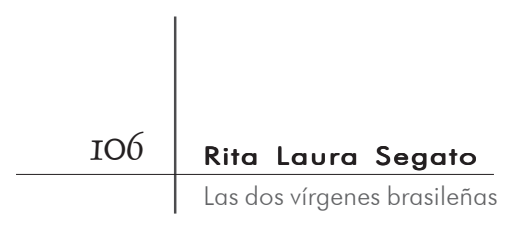

con cierto provecho pues estamos, evidentemente, frente a un culto mariano de alcance local y a otro cuya expansión es global.

En esos textos defiendo la idea de que la nación puede ser también comprendida como una formación singular de diversidad y que cada historia nacional produce fisuras históricas particulares, fraccionamientos sociales constitutivos que generan una matriz de diferencias irreductibles básicas que le son características y a las cuales otras diferencias agregadas pueden ser traducidas. En esta estructura de relaciones se vuelven reconocibles las alteridades históricas, o sea identidades constituidas a lo largo de su historia en el campo de interlocución de la nación frente a sus otros constitutivos y frente al estado, como un actor más con características y relevancia relativa, dependiendo de la nación de que se trate. En contraposición con este cuadro, como consecuencia del proceso acelerado de globalización se extienden matrices de identidad que obedecen a referentes o modelos fijos que, si bien pueden haber sido gestados en un campo de interlocución histórico propio y específico -generalmente los países centrales y especialmente Estados Unidos de Norteamérica-, salen de esta historia particular y localizada y se proponen como un horizonte global, permanente, acuñado normativo para la constitución de identidades, fuera de cualquier espacio particular. Este referente universal de identidades impone el cumplimiento de determinados requisitos y la exhibición de un repertorio definido de trazos que funcionan como marcas de las identidades globalizadas -un indio global, un negro global, un pentecostal global, un católico global, etcétera(véase Segato 1997, I998 y 1999).

Al tipificar estos dos procesos de producción de identidad, la noción de formación nacional de diversidad puede ser útil para comparar la emergencia local y nacional de la Virgen de Piedade como símbolo con la Virgen globalizada de Medjugorje. Pero, para ser más exacta, esta comparación entre las dos vírgenes necesita apoyarse en un análisis de las condiciones locales de emergencia de los cultos marianos en Medjugorje y Piedade dos Gerais, teniendo como telón de fondo una comparación entre Brasil y la antigua Yugoslavia -más específicamente la diócesis de Mostar, que hoy es parte de Bosnia-Herzegovina-.

Mart Bax, un conocedor profundo del proceso de Medjugorje, selecciona una serie de hechos que configuran el contexto relevante para comprender la emergencia del fenómeno (Bax, 


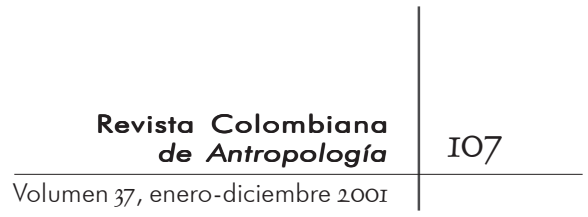

I99I). Hasta el comienzo de la década de 1960, los padres franciscanos tuvieron control absoluto sobre la pastoral de la diócesis de Mostar, en la antigua Yugoslavia, a la que pertenece la parroquia de Medjugorje. A partir de los años I960, especialmente después del Concilio Vaticano II, hubo una progresiva aproximación entre el gobierno socialista de Yugoslavia y el Vaticano. En I966, Yugoslavia y Roma firmaron un protocolo que fija derechos y obligaciones mutuas. El obispo de Mostar, monseñor Janco Vladec vé en este acuerdo la posibilidad de extender el régimen diocesano en sus parroquias, con el apoyo del Vaticano y sin conflicto con el estado socialista. Los diocesanos se alían con el estado y los sectores asociados al poder estatal, y los franciscanos, cada vez más arrinconados y despojados de sus parroquias, resisten contra el estado, junto a las masas devotas de los pequeños pueblos del interior. Respaldados entonces por el poder político nacional y por la jerarquía eclesiástica, los padres diocesanos avanzan en el dominio de las parroquias del interior del país, despojando a los franciscanos que se habían establecido en 1370 en la diócesis de Mostar.

En este contexto de eventos, en I979 el padre Branko, que por años había servido en la parroquia de Medjugorje, participó en Roma en un encuentro del Nuevo Movimiento Carismático Católico Romano. Allí, como franciscano, manifestó sus temores frente a los acontecimientos de la diócesis de Mostar y recibió dos profecías por medio de dos líderes presentes en la reunión. Ambas anticipaban el fenómeno devocional de Medjugorje. Al volver a su parroquia el padre Branko anunció el mensaje y comenzó a preparar a la grey para el evento que iría a acontecer. En 1980, en Medjugorje tuvo lugar la cura milagrosa de dos niños y al comenzar la primavera "seis niños (de la clase de catecismo) encontraron, cada uno de ellos separadamente y en lugares diferentes, rosarios franciscanos antiguos y valiosos" ( Bax, I99I: 36). Estos rosarios resultaron no ser propiedad de nadie y esto fue interpretado por el padre Branko como señal de una gracia que estaba por llegar. Finalmente, el 24 de junio de I98I sucedió la primera aparición de Nuestra Señora. Es de notar, por tanto, que estos hechos transcurrieron desde la participación del párroco franciscano de Medjugorje en la reunión de la RCC en Roma y la aparición de Nuestra Señora de la Paz.

En el modelo interpretativo adoptado por Mart Bax sectores y regímenes en competencia en el ámbito de la Iglesia son 


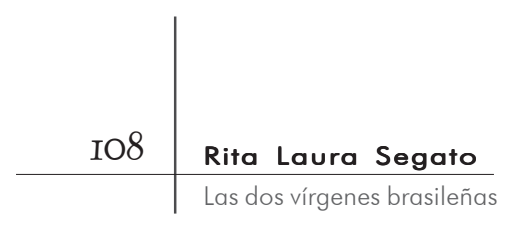

considerados relevantes y suficientes para comprender los movimientos devocionales. Éstos, a su vez, son vistos exclusivamente como epifenómenos de las divisiones y conflictos en la jerarquía eclesiástica (Ibidem: 30). Por tanto, en este modelo la cultura católica, se entiende como una consecuencia de las creaciones, movimientos e intereses de los sectores de la elite eclesiástica.

Esta interpretación, tan importante para Bax, podría ser verdadera para Bosnia-Herzegovina, pero ciertamente no lo es para Brasil. Resumiendo las circunstancias de ambos contextos vemos el cuadro siguiente: en Medjugorje las autoridades eclesiásticas locales prohíben la devoción a la aparición, las autoridades de la Iglesia nacional también lo hacen y el Vaticano no se pronuncia, pero la orden franciscana, a cargo de la pastoral en la parroquia en cuestión, apoya el fenómeno. En Brasil, todos los niveles del catolicismo, sin excepción, rechazan el fenómeno: el párroco local -franciscano-, las hermanas de la misión local, que organizan el trabajo de la comunidad eclesiástica de base, las autoridades de la Iglesia nacional y el Vaticano. Obispo y cardenal ignoran el fenómeno. Por el contrario, el pueblo laico radicado en la localidad e inmediaciones, o formado por los peregrinos que llegan de otras ciudades brasileñas, abraza el fenómeno.

A partir de la interpretación de Bax y por la forma en que aboga vehementemente por un modelo donde sólo las elites ejercen una participación real, sería posible concluir que no existe un catolicismo laico vigoroso en Europa, en el sentido de un Otro dentro de la Iglesia, con el carácter de un pueblo católico, este Otro laico y popular que, claramente, sí existe en Brasil. Por tanto, la formación de diversidad, o sea, las partes que configuran el campo católico en Europa no son las mismas que en el Brasil, y esa configuración, para Europa, se encuentra fuertemente contaminada por la manera moderna en que la nación se constituye, con el estado como una institución fuerte que participa de forma dominante en todas las esferas de la vida. En el Brasil, los niveles de institucionalización de la población son mucho más bajos y el estado está más ausente. Vemos así dos tipos de formación nacional muy diferentes: la europea, atravesada plenamente por las instituciones estatales, sea del estado Yugoslavo o, actualmente, Bosnio, sea del estado Vaticano y sus partes en pugna; la brasileña con su Otro interior, con su pueblo laico y religioso todavía constituyendo una voz alternativa. 


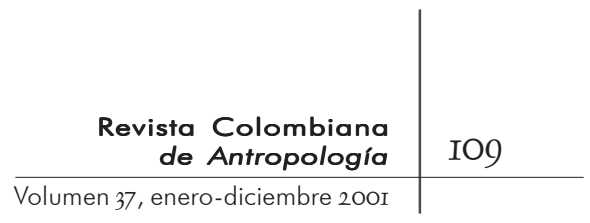

Junto con la obliteración de este Otro popular como agente, el modelo de Bax Mart también desconsidera por completo el factor puramente espiritual y no instrumentalizable, el aspecto de gratuidad, desde el punto de vista de los intereses políticos, en la constitución de los movimientos devocionales. Así, Mart afirma que en los casos en que un fenómeno devocional de este tipo no encontró sustentación en una de las fuerzas católicas en pugna, "la joven devoción tuvo una muerte pacífica", mientras que, apoyadas por un sector de la jerarquía católica, las apariciones continúan por un tiempo "largo como nunca y ocurren con la regularidad de un reloj" (Ibidem: 46). Es posible afirmar que la aparición en Piedade dos Gerais, sin apoyo de cualquier régimen oficial católico, ha continuado con la regularidad de un reloj, dos veces por día, por más de diez años.

Esto parecería probar que Brasil y Yugoslavia o, quién sabe, las naciones europeas en general, tienen formaciones de diversidad estructuradas diferentemente y, por tanto, la Virgen ocupa, en cada uno de estos ambientes nacionales, una posición y asume una función no precisamente equivalente, representando sectores de la población e intereses muy diferentes. De acuerdo con lo que el autor afirma, en Europa una población completamente penetrada, atravesada, por los estados nacional y eclesiástico, y sus partes en pugna; en Brasil, un pueblo-Otro, no estatizado y no periferializado ni por la Iglesia ni por el estado nacional.

Por tanto, el culto a la aparición de María tiene en Medjugorje un sentido local, constituyéndose en emblema del poder franciscano y en una estrategia eficaz de defensa de su régimen contra el proceso de diocesanización. Pero si emerge allí, sustentado por una de las fuerzas en pugna, se globaliza como emblema político, punta de lanza de un territorio católico y de una identidad unitaria. Su carácter dependiente en relación con la sustentación por un sector del complejo estatal católico -la orden franciscana- en el proceso de su emergencia local marca el fenómeno, lo contamina y oficializa en su proceso de difusión e implantación global. El carácter popular del fenómeno de Piedade, la radicalidad con que se encuentra en el tiempo, el paisaje bíblico en el que ya se instala, lo hacen parte de otra configuración de sentido, de otra formación de diversidad, de otro orden de espiritualidad.

Finalmente, deseo aclarar que mi diálogo inicial con Juliana no sería auténtico si no otorgase a ella la última palabra, si no la dejara ostentar algún grado de control sobre mi interpretación. Al 


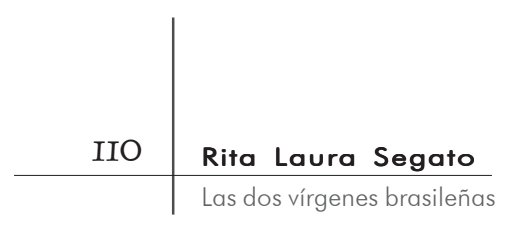

hacerlo, oímos su insistencia en que las dos vírgenes son una y la misma, afirmando con esto la coetaneidad de los dos tiempos y la convivencia posible entre las dos formaciones de diversidad. Asimismo, la insistencia de Juliana parece advertirnos también que si las manifestaciones religiosas hablan sobre el mundo y para el mundo y son proposiciones en clave, metafóricas sobre una realidad sociológica y política que las extrapola, esto no oblitera el fenómeno espiritual que constituyen sino que, por el contrario, lo vuelve más misterioso y más potente.

\section{BiBLIOGRAFÍA}

Almeida, TÂnia Mara Campos DE. 1994. A gestação de um mito: a aparición da Virgem María em Piedade dos Gerais. Dissertação de Mestrado. Universidad de Brasilia, Programa de Posgrado en Antropología Social. Brasilia.

Bax, Mart. I99I. "Marian Apparitions in Medjugorje; Rivalling Religious Regimes and State Formation in Yugoslavia". En Wolf, Eric (ed.). Religious Regimes and State Formation Perspectives from European Ethnology. Suny Press. Albany.

Campos Machado, María das Dores. 1996. Carismáticos e Pentecostais: adesão religiosa na esfera familiar. Autores Associados/São Paulo. ANPOCS. Campinas.

Carvalho, José Jorge. I998. "Religião, mídia e os predicamentos da convivência pluralista. Uma análise do evangelismo transnacional norte-americano". En Moreira, Alberto da Silva (org.). Sociedade global, cultura e religiao. Vozes. Petrópolis.

CNBB. 1994. Documento 53. Orientações Pastorais sobre a Renovação Carismática Católica. Ediciones Paulinas. São Paulo.

Gadamer, Hans-Georg. 1985. Truth and Method. Crossroads. Nueva York.

Lubel, Pe Cristovam. s/f. (folleto informativo). Aos Irmãos e às Irmãs da Renovação Carismática Católica. Cristovam Lubel. Guarapuava.

Maríz, Cecilia y María das Dores Machado. I994. "Sincretismo e trânsito religioso: comparando carismáticos e pentecostais". Comunicacoes do ISER. 45: 24-34.

NAndy, Ashis. I990. "The Politics of Secularism and the Recovery of Religious Tolerance". En Das, Veena (ed.). Mirrors of Violence. Oxford University Press. Delhi. 


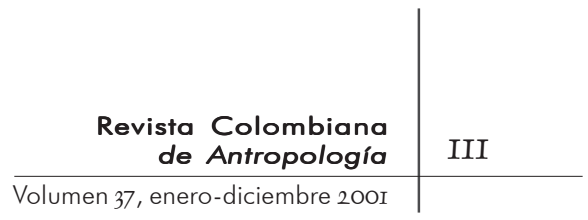

Oro, Ari Pedro.ig96. Avanço Pentecostal e Reação Católica. Vozes. Petrópolis.

Rey, Terry. I999. Our Lady of Class Struggle. The Cult of the Virgin Mary in Haiti. África World Press, Inc. Trenton, NJ/Asmara, Eritrea.

Robertson, Roland. I99I. "Globalization, Modernization, and Postmodernization: The Ambiguous Position of Religion”. En Robertson, Roland y Wiliiam Garrett (eds.). Religion and Global Order (Religion and the Political Order, vol. IV). Paragon House. Nueva York.

SAnchis, Pierre. I994. "O repto pentecostal à cultura católicobrasileira”. En Rev. de Antropología da USP. Vol. 37: I45-I8I.

Segato, Rita Laura. ig9i. "Cambio religioso y desetnificación. La expansión evangélica en los andes centrales de Argentina”. En Religiones Latinoamericanas I. México-ALER.

I997. "Formações de Diversidade: Nação e Opções Religiosas no Contexto da Globalização". En Oro, Arí Pedro y Carlos Alberto Steil (orgs.). Globalização e Religião. Vozes. Petrópolis.

I998. "The Color-blind Subject of Myth; or, Where to find Africa in the nation". Annual Review of Anthropology 27.

I999. "Identidades políticas/Alteridades históricas. Una crítica a las certezas del pluralismo global”. Anuário Antropológico 97.

Servos da Rainha. 1994. Medjugórje. Apressai a Vossa Conversção. A Mãe de Deus vem à Terra e faz o último apelo à conversão. Brasilia Servos da Rainha.

Steil, Carlos Alberto. 1996. O Sertão das Romarias. Um estudo antropológico sobre o santuário de Bom Jesus da Lapa, Bahía. Vozes e Centro de Investigação e Divulgação-CID. Petrópolis.

Velho, OtÁvio. I995. "O cativeiro da Besta-Fera". En Besta-Fera: recriação do mundo. Ensaios Críticos de Antropologia. Relume Dumará. Rio de Janeiro.

Vaz, Henrique C. DE Lima. I992. "Religião e Modernidade Filosófica". En Lucchetti Bingemer, Maria Clara (org.). O Impacto da modernidade sobre a Religião. Edições Loyola. São Paulo.

Weber, Max. 1974. Economía y sociedad. Fondo de Cultura Económica. México. 